American Journal of Immunology 3 (1): 15-24, 2007

ISSN 1553-619X

(C) 2007 Science Publications

\title{
Expression of Toll-like Receptors (TLRs) and Nucleotide-binding Oligomerization Domain (NODs) in murine peritoneal macrophages on in vitro treatment with Thymosin $\alpha 1$
}

\author{
Shikha Tarang and Ajit Sodhi \\ School of Biotechnology, Banaras Hindu University,Varanasi, INDIA-221005
}

\begin{abstract}
Thymosin $\alpha 1$ (T $\alpha 1)$ treatment of murine peritoneal macrophages in vitro induces the expression of TLRs and Nod2 proteins. Enhanced expressions of TLR2, -4, -5, -6, -7, -8, -9 and Nod2 were observed by RT-PCR and western blotting. Expression of downstream signaling molecules MyD88, IRAK1, TRAF6, IRF3 were also up regulated on treatment with T $\alpha 1$. It was also observed that pretreatment of macrophages with pharmacological inhibitors strongly down regulated the T $\alpha 1$ induced expression of TLR2,-4,-9. Macrophages pretreated with T $\alpha 1$ and then incubated with ligands for TLRs - Zymosan A, LPS and CpG DNA, showed significantly enhanced production of proinflammatory cytokines, than the macrophages treated with ligands alone. This suggests that pretreatment of macrophages with $\mathrm{T} \alpha 1$ makes them functionally more responsive to further challenge with TLR ligands.
\end{abstract}

Key words: Macrophages activation; TLRs; Thymosin $\alpha$ 1; Cytokines

\section{INTRODUCTION}

TLRs and their homologues play an essential role in initiating the innate immune response against pathogens in organisms as diverse as plants, insects and mammals $[1,2]$. They are expressed in a variety of cell types, including both immune and non-immune cells and their expression patterns are distinct in each cell type ${ }^{[3,4]}$. TLRs are localized in different compartments of cells, such as on the surface (TLR1, $-2,-4,-5-6,10)$ or in the cytoplasm (TLR3, -7, -8, -9). These localizations are most likely to facilitate the encounters with their diverse ligands ${ }^{[5]}$. TLRs are type I integral membrane glycoproteins, with molecular weights ranging from 90$115 \mathrm{kDa}$. As a primary class of pattern recognition receptor (PRR) molecules, they are characterized by the presence of Toll/IL-1 receptor (TIR) domain in their cytoplasmic region and unique leucine rich repeats (LRRs) in their extra cellular portion, which is believed to interact directly with their putative ligands ${ }^{[6,7,8]}$. TLRs recognize and respond to diverse molecules of microbial origin and serve as a crucial link between the innate and adaptive immune responses ${ }^{[9]}$. Recently, TLR expression is reported to get modulated in response to a variety of synthetic as well host derived molecules ${ }^{[10]}$. On recognition of ligands, TLRs induce complex intracellular signaling events involving MyD88, IRAK1, TRAF6, culminating in the activation of NF- $\mathrm{KB}$, MAP kinases and IRF proteins [8,11-13]. However, since TLRs recognize pathogens at the cell surface or lysosome/endosome membranes, TLR system is not used for the detection of pathogens which have invaded the cytosol ${ }^{[14]}$. The pathogens which have invaded the cytosol are detected by various cytoplasmic PRRs, which activate a number of signaling pathways. The first intracellular microbial sensors discovered were the Nucleotide-binding Oligomerization Domain, Nod1 and Nod2 proteins. Because of the presence of LRR domains, these proteins are believed to be involved in innate immunity ${ }^{[15]}$. Recently, Nod proteins have been shown to play a key role in host defence to different pathogens. Nod1 is involved in host defense towards intracellular pathogens including Shigella flexneri, enteroinvasive E. coli, Pseudomonas aeruginosa as well as $H$. pylori ${ }^{[15,16]}$. Nod2 is involved in sensing of Streptococcus pneumoniae and Mycobacteria ${ }^{[17,18]}$.

Thymosin $\alpha 1$ (T $\alpha 1)$ is 28 amino acid peptide, generated by proteolytic cleavage of a larger bioactive molecule, prothymosin alpha- 1 and originally isolated from bovine thymus. As an immune adjuvant in

Corresponding Author: Ajit Sodhi, School of Biotechnology, Banaras Hindu University, Varanasi-221005, INDIA, Tel: + 91-542-2368331, Fax: +91-542-2368693 
vaccines, synthetic preparation of $\mathrm{T} \alpha 1$ is in clinical trials worldwide ${ }^{[19,20]}$. Recently, it has been reported that T $\alpha 1$ activates TLR signaling pathway for the induction of antifungal resistance in dendritic cells (DCs). T $\alpha 1$ also induces the functional maturation and interleukin-12 production by dendritic cells through the p38 mitogen activated protein kinase/NF- $\mathrm{kB}$ pathway [21]. The activation of $\mathrm{T} \alpha 1$ has also been shown to induce the formation of TRAF6-p62-PKC complex and enhances the production of IL-6 in murine bone marrow derived macrophages (BMDM) ${ }^{[20]}$. Enhanced production of cytokines and CSFs, is induced in peripheral blood lymphocytes in response to $\mathrm{T} \alpha 1$ treatment ${ }^{[21]}$. Recently, we have reported that anticancer drug, cisplatin and a lectin derived from Canavalia ensiformis, Con A induces the expression of Toll-like Receptors in murine peritoneal macrophages $[22,23]$. In the present studies, we investigated the effect of T $\alpha 1$ on TLR gene and protein expression in murine peritoneal macrophages. The involvement of MAPK and NF- $\mathrm{KB}$ in $\mathrm{T} \alpha 1$ induced TLR signaling was also studied. Further, we analyzed the contribution of the T $\alpha 1$ induced enhanced TLRs expression to the cytokine production by macrophages, following stimulation with TLR ligands. Several reports have suggested the possible involvement of either Nod1 or Nod2 in TLRdriven signaling ${ }^{[15]}$. Since Nod1 and Nod2 also contain LRR domains (similar to TLRs), we further checked the expression of these intracellular PRRs in T $\alpha 1$ treated macrophages in murine peritoneal macrophages.

\section{MATERIALS AND METHODS}

Mice: Inbred strains of BALB/c mice of either sex at 810 weeks $(20-22 \mathrm{gm})$ of age were used for obtaining peritoneal macrophages.

Cell cultures and reagents: Macrophage monolayers were cultured in RPMI 1640 medium supplemented with heat-inactivated fetal calf serum $(10 \%)$, penicillin $(100 \mathrm{U} / \mathrm{ml})$, streptomycin $(100 \mathrm{U} / \mathrm{ml})$ and gentamycin $(20 \mu \mathrm{g} / \mathrm{ml})$ at $37^{\circ} \mathrm{C}$ in humidified air containing $5 \% \mathrm{CO}_{2}$. Medium RPMI 1640, Tri-reagent, Thymosin $\alpha 1$, Zymosan A and LPS were purchased from SigmaAldrich, St. Louis, Missouri, USA. Fetal calf serum was from Biological Industries, Haemek, Israel. Positive ligands for TLR3 and TLR9, Poly I:C and CpG DNA were kind gift from Dr. Bruce Beutler, Scripps Research Institute, California, USA. Polyclonal antibodies specific for TLR1, -2, -3, -4, -6, -7, -8, -9, MyD88, IRAK1, TRAF6, IRF3, phospho-Iк $\beta$, phosphoJNK, phospho-p38, phospho-p42/44, iNOS, actin and HRP-conjugated anti-rabbit, anti-mouse, anti-goat IgGs was purchased from Santa Cruz Biotechnology,
California, USA. TLR5 antibody was purchased from Imgenex, California, USA. One step RT-PCR kit was from Qiagen, Germany. Mouse primers for TLRs 1-9 were purchased from GENSET Singapore Biotech. Pvt. Ltd., Singapore. SP600125, SB202190 and PD98059 were purchased from Calbiochem, La Jolla, CA, USA. Curcumin was a gift from Unico Pharmaceuticals, Ludhiana, India. ELISA kits were purchased from BD Pharmingen, California, USA. All the reagents were endotoxin-free as determined by the Limulus amoebocyte lysate assay (sensitivity limit, $0.1 \mathrm{ng} / \mathrm{ml}$ ).

Isolation and activation of macrophages:Macrophage monolayers were prepared as described previously ${ }^{[25]}$. Peritoneal exudate cells were harvested from peritoneal cavity using chilled serum-free RPMI 1640 medium and added to wells of 24-well tissue culture plates (Nunc, Denmark). After $2 \mathrm{hr}$ of incubation at $37^{\circ} \mathrm{C}$ in an atmosphere of $5 \% \mathrm{CO}_{2}$, non-adherent cells were removed by washing (3 times) with warm serum-free medium and the adherent cells were further incubated in complete medium overnight to form macrophage monolayers. More than $95 \%$ of the adherent cell population was macrophages as determined by morphology and non-specific esterase staining. Ta1 $(100 \mathrm{ng} / \mathrm{ml})^{[26]}$ treatment was given for different time intervals in fresh medium. Similarly, macrophage monolayers were treated with positive ligands for TLRs: Zymosan A ( $10 \mu \mathrm{g} / \mathrm{ml})$, PolyI: C $(25 \mu \mathrm{g} / \mathrm{ml})$, LPS $(10 \mu \mathrm{g} / \mathrm{ml})$ and $\mathrm{CpG}$ DNA $(1.5 \mu \mathrm{M})$ for different time intervals ${ }^{[27-30]}$.

In another set of experiments, the macrophage monolayers were preincubated with JNK inhibitor SP600125 $(10 \mu \mathrm{M})$ or p38 inhibitor SB202190 $(10 \mu \mathrm{M})$ or p42/44 inhibitor PD98059 $(10 \mu \mathrm{M})$ or NF-кB inhibitor curcumin $(10 \mu \mathrm{M})$ for 1 hour ${ }^{[31,32]}$. Thereafter, medium was removed, cells were washed with warm medium and further incubated in fresh medium with $\mathrm{T} \alpha 1(100 \mathrm{ng} / \mathrm{ml})$ for $18 \mathrm{hr}$. Western blotting of samples was done as described.

RNA isolation, Reverse Transcription and Polymerase Chain Reaction (RT-PCR):Total RNA was isolated from the macrophages by Tri-reagent in accordance with the supplier's instructions. The RNA was reverse-transcribed using a Qiagen one-step RTPCR kit and amplified by PCR using the specific murine primers indicated in the 'Results'. The thermo cycle conditions were 30 cycles of $94^{\circ} \mathrm{C}$ for $1 \mathrm{~min}, 55^{\circ} \mathrm{C}$ for $1 \mathrm{~min}$ and $72^{\circ} \mathrm{C}$ for $2 \mathrm{~min}$, after which an additional extension step at $72^{\circ} \mathrm{C}$ for $10 \mathrm{~min}$ was included. Electrophoresis of amplified cDNA was carried out on a $2 \%$ agarose gel and stained with ethidium bromide. 
The murine primer sequences are as follows:

TLR1 forward

5'-GGCACGTTAGCACTGAGACTC- 3'

TLR1 reverse

5'-GGTGGATATTCTTATTGCTGTGTG- 3'

TLR2 forward

5 -GGAGCGGCGGCTGCAGGACTC- 3'

TLR2 reverse

5'-CCAAAGAGCTCGTAGCATCC- 3'

TLR3 forward

5' -CACAGGCTGAGCAGTTTGAA- 3'

TLR3 reverse

5' -TTTCGGCTTCTTTTGATGCT- 3'

TLR4 forward

5'-AGTGGGTCAAGGAACAGAAGCA- 3'

TLR4 reverse

5'-CTTTACCAGCTCATTTCTCACC-3'

TLR5 forward

5' -GAATTCCTTAAGCGACGTAA- 3'

TLR5 reverse

5' -GAGAAGATAAAGCCGTGCGA- 3'

TLR6 forward

5' -AGTGCTGCCAAGTTCCGACA- 3'

TLR6 reverse

5' -AGCAAACACCGAGTATAGCG- 3'

TLR7 forward

5' -AATCCACAGGCTCACCCATA- 3'

TLR7 reverse

5' -CAGGTACCAAGGGATGTCCT- 3'

TLR8 forward

5'-GACATGGCCCCTAATTTCCT- 3'

TLR8 reverse

5'-GACCCAGAAGTCCTCATGGA- 3'

TLR9 forward

5' -CCAGACGCTCTTCGAGAACC- 3'

TLR9 reverse

5' -GTTATAGAAGTGGCGGTTGT- 3'

GAPDH forward

5'-CCTGCAGTGTCTGATATTGTTG- 3'

GAPDH reverse

\section{5'-AACACACCATTGCGATGAA- 3'}

The expression of housekeeping gene GAPDH was checked for each set of RT-PCR experiment, as shown in lower panel. The possible contamination of any PCR component was excluded by performing a PCR reaction with these components in the absence of RT product in each set of experiment (negative control).

Preparation of cell lysates and immunoblotting:The macrophage monolayers with or without treatment with T $\alpha 1$ were washed with ice cold phosphate buffered saline containing $1 \mathrm{mM} \mathrm{Na}_{3} \mathrm{VO}_{4}$, then lysed in $50 \mu \mathrm{l}$ of lysis buffer $[20 \mathrm{mM}$ Tris-HCl, $\mathrm{pH} 8,137 \mathrm{mM} \mathrm{NaCl}$, $10 \%$ glycerol (v/v), $1 \%$ Triton X-100 (v/v), $1 \mathrm{mM}$

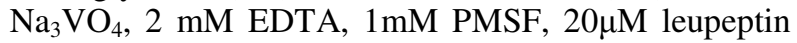
and 0.15 units $/ \mathrm{ml}$ aprotonin] for $20 \mathrm{~min}$ at $4^{\circ} \mathrm{C}$. The lysates were centrifuged at $10000 \mathrm{xg}$ for $10 \mathrm{~min}$. To the supernatants (containing Triton X-100 soluble proteins), added $50 \mu \mathrm{l}$ of sample buffer, boiled for 3-5 min. Samples were separated on $10 \%$ SDSpolyacrylamide gels at $20 \mathrm{~mA}$. The separated proteins were transferred to nitrocellulose membrane $(1 \mathrm{hr}$ at 125V using Bio-Rad Mini Trans Blotter). The transferred proteins on the membrane were then immunoblotted with primary antibody, incubated with horseradish peroxidase conjugated secondary antibody and visualized by the Chemiluminescence Western Blotting Kit (Santa Cruz Biotechnology Inc., California, USA). To monitor equal loading of protein, western blot analysis using antibody directed against actin was done for each experiment, as shown in lower panels.

Assay for TNF- $\alpha$, IL-1ß, IL-12 and IFN- $\gamma$ : In one set of experiments, the macrophage monolayers $\left(1 \times 10^{6}\right.$ cells/well) were treated with $\mathrm{T} \alpha 1 \quad(100 \mathrm{ng} / \mathrm{ml})$ or Zymosan A $(10 \mu \mathrm{g} / \mathrm{ml})$ or Poly I:C $(25 \mu \mathrm{g} / \mathrm{ml})$ or LPS $(10 \mu \mathrm{g} / \mathrm{ml})$ or $\mathrm{CpG}$ DNA $(1.5 \mu \mathrm{M})$ for $28 \mathrm{hr}$. In another set, macrophage monolayers were pretreated with $\mathrm{T} \alpha 1$ for $12 \mathrm{hr}$, washed and further incubated for $16 \mathrm{hr}$ with or without TLR2 ligand, Zymosan A $(10 \mu \mathrm{g} / \mathrm{ml})$ or TLR3 ligand, Poly I:C $(25 \mu \mathrm{g} / \mathrm{ml})$ or TLR4 ligand, LPS $(10 \mu \mathrm{g} / \mathrm{ml})$ or TLR9 ligand, CpG DNA $(1.5 \mu \mathrm{M})$. Supernatants from both the experiments were collected assayed for NO, TNF- $\alpha$, IL-1 $\beta$, IL-12 and IFN- $\gamma$. Cytokines were measured using sandwich ELISA kits from BD Pharmingen, San Diego, California, USA. NO was assayed as described below.

Nitrite assay estimation of NO production:The concentration of stable nitrite, the end product from NO generation by macrophages was determined by the method of Ding et al. (1998) based on Griess reaction ${ }^{[33]}$. $100 \mu \mathrm{l}$ of culture supernatants were incubated with equal volume of Griess reagent (one part $1 \%$ w/v sulphanilamide in $2.5 \% \mathrm{v} / \mathrm{v} \mathrm{H}_{3} \mathrm{PO}_{4}$ plus one part of $0.1 \% \mathrm{w} / \mathrm{v}$ napthyl-ethylene-diamine dihydrochlroride in distilled water: two parts mixed just before use) at $37^{\circ} \mathrm{C}$ for 10 minutes in a 96-well ELISA plate (Nunc, Roskilde, Denmark). The absorbance at $540 \mathrm{~nm}$ was measured with Emax microplate reader (Molecular Devices Corporation, California, USA). Nitrite content $\left(\mu \mathrm{M} / 10^{6}\right.$ cells) was quantified by extrapolation from sodium nitrite standard curve in each experiment.

Statistical analysis: Statistical analysis between different groups was analyzed by ANOVA. 


\section{RESULTS}

Expression of TLR mRNA and protein in macrophages after $\mathbf{T} \alpha 1$ treatment: Murine peritoneal macrophages treated with $\mathrm{T} \alpha 1(100 \mathrm{ng} / \mathrm{ml})$ in vitro for 3 , 6,12 and $18 \mathrm{hr}$, resulted in enhanced expression of TLR2, -4, -5, -6, -7, -8, -9. The maximum expression of TLR2,-4,-8,-9 mRNA was observed at $3 \mathrm{hr}$ of Ta1 treatment (Fig.1-4). TLR6 mRNA was expressed $6 \mathrm{hr}$ after T $\alpha 1$ treatment (Fig.1) whereas expression of TLR5 and TLR7 mRNA was observed after $18 \mathrm{hr}$ and 3-12 hr of $\mathrm{T} \alpha 1$ treatment respectively (Fig.3).

Similarly, macrophages treated with $\mathrm{T} \alpha 1$ showed enhanced expression of TLR proteins between 12-18 hr. Expression of TLR4, -7, -8 was observed at $12-18 \mathrm{hr}$ of treatment (Fig.2\&3) whereas expression of TLR2, -5, $6,-9$ proteins was observed only after $18 \mathrm{hr}$ of Tal treatment (Fig.1,3\&4). Specific known TLR ligands were used as positive control. It may be noted that $\mathrm{T} \alpha 1$ did not induce the expression of TLR3 protein (data not shown).

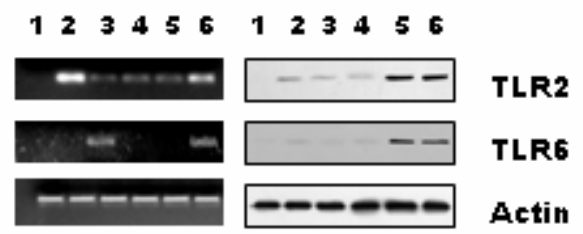

Fig.1: Effect of T $\alpha 1(100 \mathrm{ng} / \mathrm{ml})$ treatment on TLR2 and TLR6 mRNA/protein expression in macrophages. Lane-1, untreated; Lane-2, $3 \mathrm{hr}$ treatment; Lane-3, $6 \mathrm{hr}$ treatment; Lane-4, $12 \mathrm{hr}$ treatment; Lane-5, $18 \mathrm{hr}$ treatment; Lane-6, Zymosan A $(10 \mu \mathrm{g} / \mathrm{ml}) 12 \mathrm{hr}$ treatment. The figure is representative of three independent experiments with similar results.

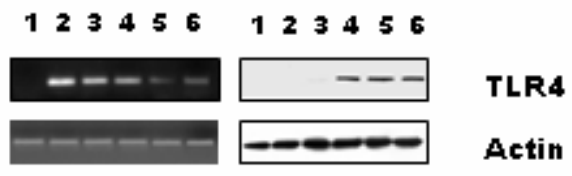

Fig.2: Effect of Ta1 (100ng/ml) treatment on TLR4 $\mathrm{mRNA} /$ protein expression in macrophages. Lane-1, untreated; Lane-2, $3 \mathrm{hr}$ treatment; Lane-3, $6 \mathrm{hr}$ treatment; Lane-4, $12 \mathrm{hr}$ treatment, Lane-5, $18 \mathrm{hr}$ treatment; Lane-6, LPS $(10 \mu \mathrm{g} / \mathrm{ml}) 12 \mathrm{hr}$ treatment. The figure is representative of three independent experiments with similar results.

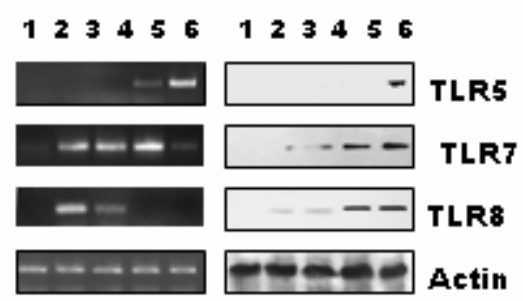

Fig.3: Effect of T $\alpha 1$ (100ng/ml) treatment on TLR5, -7, $-8 \mathrm{mRNA} /$ protein expression in macrophages. Lane-1, untreated; Lane-2, $3 \mathrm{hr}$ treatment; Lane3, $6 \mathrm{hr}$ treatment; Lane-4, $12 \mathrm{hr}$ treatment, Lane$5,18 \mathrm{hr}$ treatment. The figure is representative of three independent experiments with similar results.

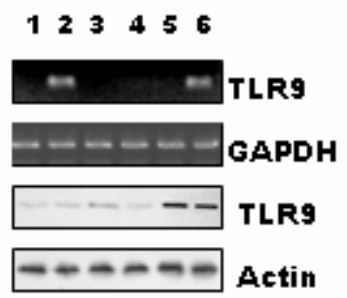

Fig.4: Effect of T $\alpha 1(100 \mathrm{ng} / \mathrm{ml})$ treatment on TLR9 $\mathrm{mRNA} /$ protein expression in macrophages. Lane-1, untreated; Lane-2, $3 \mathrm{hr}$ treatment; Lane3, $6 \mathrm{hr}$ treatment; Lane-4, $12 \mathrm{hr}$ treatment, Lane$5,18 \mathrm{hr}$ treatment, Lane- 6 , CpG DNA $(1.5 \mu \mathrm{M})$ $12 \mathrm{hr}$ treatment. The figure is representative of three independent experiments with similar results.

Expression of MyD88, IRAK1 and TRAF6 in macrophages after Ta1 treatment: Enhanced expression TLR associated proteins - MyD88, IRAK, TRAF6 was observed between 6-36 hr in macrophages treated with T $\alpha 1$ (Fig.5).

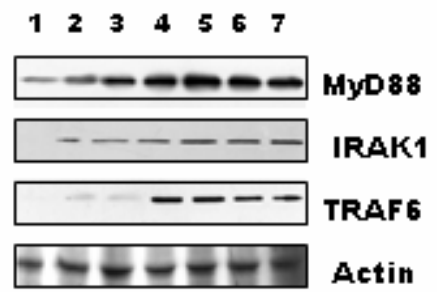

Fig.5: Effect of T $\alpha 1(100 \mathrm{ng} / \mathrm{ml})$ treatment on MyD88, IRAK1 and TRAF6 protein expression in macrophages. Lane-1, untreated; Lane-2, $6 \mathrm{hr}$ treatment; Lane-3, $12 \mathrm{hr}$ treatment; Lane-4, 18 $\mathrm{hr}$ treatment, Lane-5, $24 \mathrm{hr}$ treatment; Lane-6, $36 \mathrm{hr}$ treatment; Lane-7, LPS $(10 \mu \mathrm{g} / \mathrm{ml}) 12 \mathrm{hr}$ treatment. The figure is representative of three independent experiments with similar results. 
Expression of IRF3 in macrophages after Ta1 treatment: Macrophages treated with $\mathrm{T} \alpha 1$ showed enhanced expression of IRF3 protein after $24 \mathrm{hr}$ of treatment (Fig.6).

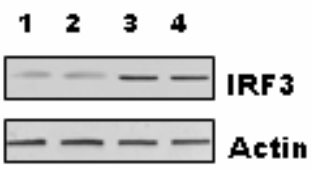

Fig.6: Effect of T $\alpha 1(100 \mathrm{ng} / \mathrm{ml})$ treatment on IRF3 protein expression in macrophages. Lane-1, untreated; Lane-2, $18 \mathrm{hr}$ treatment; Lane-3, $24 \mathrm{hr}$ treatment; Lane-4, LPS $(10 \mu \mathrm{g} / \mathrm{ml}) \quad 18 \mathrm{hr}$ treatment. The figure is representative of three independent experiments with similar results.

Expression of NOD1 and NOD2 proteins in T $\alpha 1$ treated macrophages: The expression of NOD1 and NOD2 in murine peritoneal macrophages was studied after stimulation with T $\alpha 1$, cisplatin and Con A. It is observed that $T \alpha 1$ and Con $A$ induced the expression of NOD2 mRNA and protein but not NOD1. However cisplatin treatment of macrophages induced the expression of both Nod1 and Nod2 mRNA and protein (Fig.7).

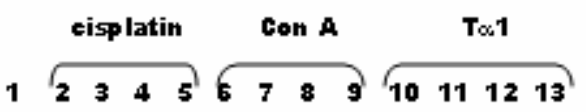

a.

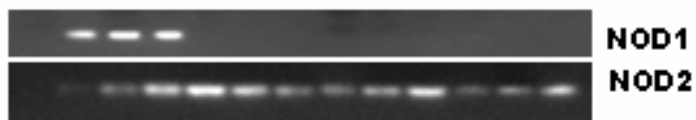

Fig.7a: RT-PCR analysis of Nod1 and Nod2 mRNA expression in macrophages on treatment with cisplatin $(5 \mu \mathrm{g} / \mathrm{ml})$, Con A $(10 \mu \mathrm{g} / \mathrm{ml})$ and $\mathrm{T} \alpha 1$ (100ng/ml). Lane-1, untreated; Lane-2, cisplatin $2 \mathrm{hr}$ treatment; Lane-3, cisplatin $4 \mathrm{hr}$ treatment; Lane-4, cisplatin $8 \mathrm{hr}$ treatment; Lane-5, cisplatin $12 \mathrm{hr}$ treatment; Lane-6, Con A $2 \mathrm{hr}$ treatment; Lane-7, Con A $4 \mathrm{hr}$ treatment; Lane-8, Con A $8 \mathrm{hr}$ treatment; Lane-9, Con A $12 \mathrm{hr}$ treatment; Lane-10, T $\alpha 1$ $2 \mathrm{hr}$ treatment; Lane-11, T $\alpha 14 \mathrm{hr}$ treatment; Lane-12, T $\alpha 18 \mathrm{hr}$ treatment; Lane-12, T $\alpha 112$ $\mathrm{hr}$ treaatment. The figure is representative of three independent experiments with similar results.

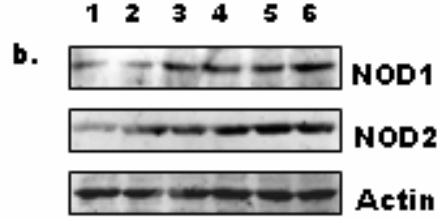

Fig.7b: Western blot analysis of Nod1 and Nod2 protein expression in macrophages on treatment with cisplatin $(5 \mu \mathrm{g} / \mathrm{ml})$. Lane-1, untreated; Lane-2, $2 \mathrm{hr}$ treatment; Lane-3, $4 \mathrm{hr}$ treatment; Lane-4, $8 \mathrm{hr}$ treatment; Lane-5, 12 $\mathrm{hr}$ treatment; Lane-6, $18 \mathrm{hr}$ treatment. The figure is representative of three independent experiments with similar results.

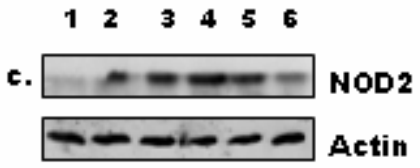

Fig.7c: Western blot analysis of Nod2 protein expression in macrophages on treatment with Con A $(10 \mu \mathrm{g} / \mathrm{ml})$. Lane-1, untreated; Lane-2, $2 \mathrm{hr}$ treatment; Lane-3, $4 \mathrm{hr}$ treatment; Lane-4, $8 \mathrm{hr}$ treatment; Lane-5, $12 \mathrm{hr}$ treatment; Lane$6,18 \mathrm{hr}$ treatment. The figure is representative of three independent experiments with similar results.

$$
\begin{array}{llllll}
1 & 2 & 3 & 4 & 5 & 6
\end{array}
$$

\section{d.}

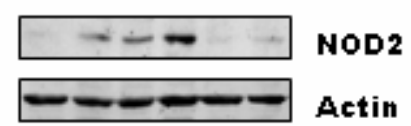

Fig.7d: Western blot analysis of Nod2 protein expression in macrophages on treatment with T $\alpha 1$ (100ng/ml). Lane-1, untreated; Lane-2, 2 hr treatment; Lane-3, 4 hr treatment; Lane-4, 8 hr treatment; Lane-5, 12 hr treatment; Lane-6, $18 \mathrm{hr}$ treatment. The figure is representative of three independent experiments with similar results.

Ta1 activates MAP Kinase- p42/44, p38 and JNK and transcription factor NF- $\kappa B$ in a time dependent manner: Treatment of macrophages with T $\alpha 1$ (100 $\mathrm{ng} / \mathrm{ml}$ ) for various time intervals resulted in the phosphorylation of p42/44, p38 and JNK. The maximum activation (phosphorylation) was observed at 15 minutes (Fig.8). Maximum expression of phosphoI-kB was observed between 30-60 minutes (Fig.9). 
$\begin{array}{llllll}1 & 2 & 3 & 4 & 5 & 6\end{array}$

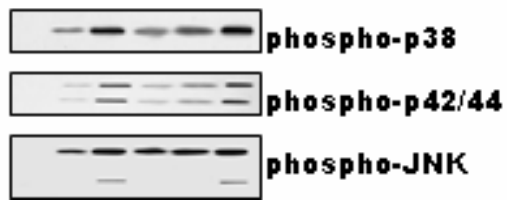

Fig.8: Western blot analysis of phosphor-p38, phosphor-p42/44, phosphor-JNK expression in macrophages after $\mathrm{T} \alpha 1(100 \mathrm{ng} / \mathrm{ml})$ treatment Lane-1, untreated; Lane-2, 5 min treatment; Lane-3, $15 \mathrm{~min}$ treatment; Lane-4, $30 \mathrm{~min}$ treatment; Lane-5, 60 min treatment; Lane-6, LPS $(10 \mu \mathrm{g} / \mathrm{ml}) 15 \mathrm{~min}$ treatment. The figure is representative of three independent experiments with similar results.

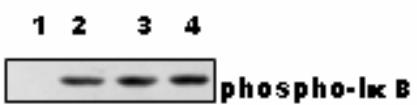

Fig.9: Western blot analysis of phospho-I- $\kappa \beta$ expression in macrophages after $\mathrm{T} \alpha 1(100 \mathrm{ng} / \mathrm{ml})$ treatment. Lane-1, untreated; Lane-2, $30 \mathrm{~min}$ treatment; Lane-3, 60 min treatment; Lane-4, LPS $(10 \mu \mathrm{g} / \mathrm{ml}) 60 \mathrm{~min}$ treatment. The figure is representative of three independent experiments with similar results.

Pharmacological inhibitors of MAP kinases and NFKB block the expression of TLR2, $-4,-9$ proteins: The T $\alpha 1$ induced protein expression of TLR2, -4, -9 was strongly inhibited in macrophages pretreated with inhibitors of MAP kinase pathways - JNK inhibitorSP600125, p38 inhibitor-SB202190, p42/44 inhibiterPD98059 or NF-kB inhibitor- curcumin for 1 ho (Fig.10).

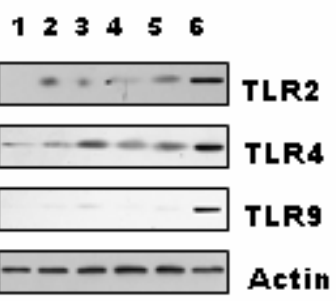

Fig.10: Western blot analysis of the effect of SP600125 (inhibitor of JNK), SB202190 (inhibitor of p38), PD98059 (inhibitor of p42/44) and curcumin (inhibitor of NF- $\mathrm{BB}$ ) on expression of TLR protein in $\mathrm{T} \alpha 1(100 \mathrm{ng} / \mathrm{ml})$ treated macrophages. Lane-1, untreated; Lane-2, SP600125 $(10 \mu \mathrm{m})+$ T $\alpha 1$; Lane-3, SB202190 $(10 \mu \mathrm{m})+\mathrm{T} \alpha 1$; Lane-4, PD98059 $(10 \mu \mathrm{m})+\mathrm{T} \alpha 1$; Lane-5, curcumin $(10 \mu \mathrm{m})+\mathrm{T} \alpha 1$; Lane- 6 , T $\alpha 1$. The figure is representative of three independent experiments with similar results.
Production of nitric oxide and proinflammatory cytokines on treatment with TLR ligands after Ta1 priming: Macrophages treated for $28 \mathrm{hr}$ with Ta1 or with TLR ligands were observed to produce significantly enhanced NO, TNF- $\alpha$, IL- $1 \beta$, IL-12, IFN$\gamma$, than the untreated macrophages. When macrophages pretreated with $\mathrm{T} \alpha 1$ for $12 \mathrm{hr}$, washed and subsequently incubated for additional $16 \mathrm{hr}$, with TLR ligands; Zymosan A, LPS and CpG DNA there was further and significantly enhanced production of nitric oxide and proinflammatory cytokines, as compared to macrophages incubated with TLR ligands alone. However, macrophages treated with Ta1, washed and incubated with Poly I:C, did not show any further enhancement in cytokine production as compared to macrophages treated with $T \alpha 1$ alone (Fig.11\&12). The macrophages treated for $12 \mathrm{hr}$ with $\mathrm{T} \alpha 1$, washed and further incubated for $16 \mathrm{hr}$ without any TLR ligand did not produce any significant amounts of $\mathrm{NO}$ and proinflammatory cytokines.

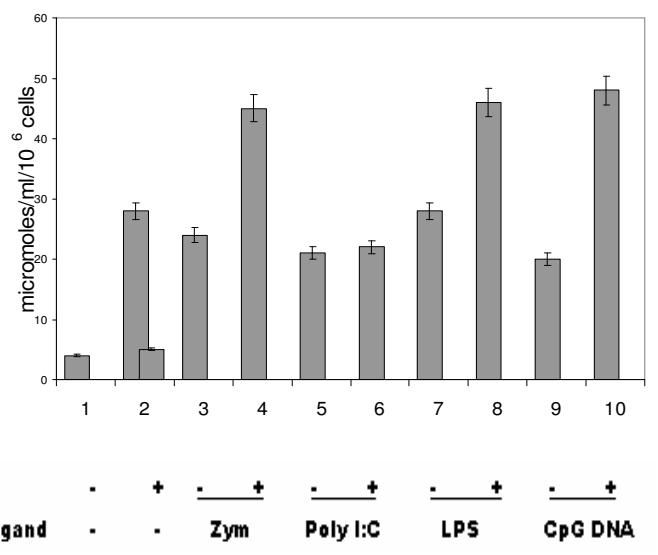

Fig.11: Effect of T $\alpha 1$ priming (macrophage pretreated with $100 \mathrm{ng} / \mathrm{ml}$ of $\mathrm{T} \alpha 1$ for $12 \mathrm{hr}$ ) on production of NO on further incubation with TLR ligands for $16 \mathrm{hr}$ - Zymosan A (10 $\mu \mathrm{g} / \mathrm{ml})$ (Zym), Poly I:C $(25 \mu \mathrm{g} / \mathrm{ml})$, LPS $(10 \mu \mathrm{g} / \mathrm{ml})$, CpG DNA (1.5 $\mu \mathrm{m})$. Macrophages pretreated with $\mathrm{T} \alpha 1$ for 12 $\mathrm{hr}$ and further incubated in fresh medium for additional $16 \mathrm{hr}(*)$ produced insignificant amount of NO. (\#) indicates $P$ values $<0.05$ of relative cytokine production in the presence $(+)$ or absence (-) of T $\alpha 1$. Bar represents the standard errors. The figure is representative of three independent experiments with similar results. 


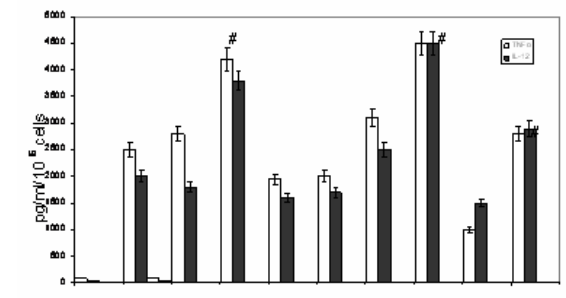

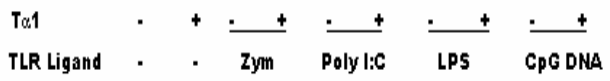

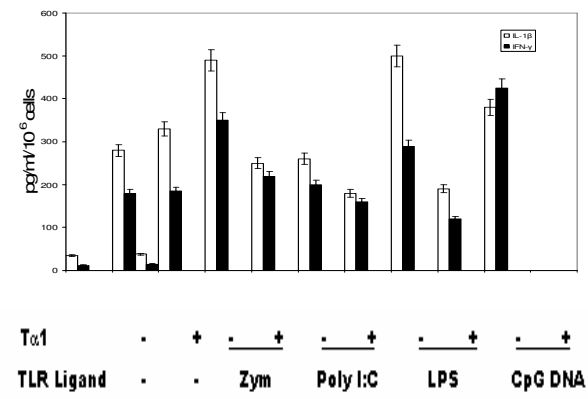

Fig.12: Effect of T $\alpha 1$ priming (macrophage pretreated with $100 \mathrm{ng} / \mathrm{ml}$ of $\mathrm{T} \alpha 1$ for $12 \mathrm{hr}$ ) on production of TNF- $\alpha$, IL-12 (a), IFN- $\gamma$, IL-12 (b), on further incubation with TLR ligands for $16 \mathrm{hr}$ Zymosan A $(10 \mu \mathrm{g} / \mathrm{ml})$ (Zym), Poly I:C $(25 \mu \mathrm{g} / \mathrm{ml})$, LPS $(10 \mu \mathrm{g} / \mathrm{ml})$, CpG DNA $(1.5$ $\mu \mathrm{m})$. Macrophages pretreated with T $\alpha 1$ for 12 $\mathrm{hr}$ and further incubated in fresh medium for additional $16 \mathrm{hr}(*)$ produced insignificant amount of cytokines. (\#) indicates $P$ values $<0.05$ of relative cytokine production in the presence (+) or absence (-) of Ta1. Bar represents the standard errors. The figure is representative of three independent experiments with similar results.

\section{DISCUSSION}

In the present studies it is observed that $\mathrm{T} \alpha 1$ induces a significantly enhanced transcription of different TLR genes and their protein expression in murine peritoneal macrophages. In addition to TLRs, the expression of cytosolic pattern recognition receptor, NOD2 is also up regulated on treatment with $\mathrm{T} \alpha 1$.

It has been reported that $T \alpha 1$ induces the expression of TLR2, TLR5, TLR8 and TLR9 in dendritic cells, through MyD88 dependent pathway. Loss of MyD88 abolished the $T \alpha 1$ induced protection of mice from Aspergillus infection ${ }^{[21]}$. In the present investigations, it is reported that T $\alpha 1$ induces the expression of TLR2, $-4,-5,-6,-7,-8,-9$ in murine peritoneal macrophages. Ta1 did not induce the expression of TLR3. It may be noted, that TLR2, -4, -5, -6, -7, -8, -9 involves MyD88 signaling pathway, whereas TLR3 and TLR4 can activate MyD88 independent pathway. TLR4 is unique in its ability to activate both, MyD88-dependent as well as MyD88-independent responses ${ }^{[34,35]}$. Since Ta $1 \mathrm{did}$ not induce the expression of TLR3, it is suggested that T $\alpha 1$ activates macrophages through MyD88-dependent signaling pathway. This observation is further supported by the fact that $\mathrm{T} \alpha 1$ primed macrophages on treatment with TLR3 ligand Poly I:C did not show enhanced production of $\mathrm{NO}$ and proinflammatory cytokines (Fig.11\&12).

Because of the presence of LRR domains (similar to TLRs), transcriptional profile of Nod1 and Nod2 genes and protein expression were also studied in macrophages on treatment with $T \alpha 1$. Interestingly, $T \alpha 1$ induced the gene transcription of Nod2 and expression of Nod2 protein in macrophages. T $\alpha 1$ did not induce the Nod1 gene transcription and its protein expression. We have previously reported that, cisplatin and Con A induces the expression of TLRs in macrophages ${ }^{[22,23]}$. While investigating the expression of Nod1 and Nod2, it is observed that T $\alpha 1$ and Con A treatment of macrophages induced the expression of Nod2 only, while the cisplatin treatment resulted in the gene transcription and protein expression of both Nod1 and Nod2 (Fig.7).

We further investigated the role of MAP kinases and NF- $\kappa B$ pathways in T $\alpha 1$ induced expression of TLRs. It was observed that pretreatment of macrophages with JNK inhibitor-SP600125, p38 inhibitor-SB202190, p42/44 inhibitor-PD98059 or NF- $\kappa B$ inhibitorcurcumin, blocks the expression of TLR2,-4,-9 (Fig.11). This suggests that MAP kinases and NF- $\mathrm{kB}$ pathways play an active role in $\mathrm{T} \alpha 1$ induced expression of TLRs and macrophage activation.

Murine peritoneal macrophages treated with $\mathrm{T} \alpha 1$ or Zymosan A or Poly I:C or LPS or CpG DNA for $28 \mathrm{hr}$ showed enhanced production of nitric oxide (NO), TNF- $\alpha$, IL-1 $\beta$, Il-12 and IFN- $\gamma$, as compared to control (Fig.11\&12) In an another set of experiments, when murine peritoneal macrophages treated with $T \alpha 1$ for 12 $\mathrm{hr}$, washed and subsequently further incubated with TLR-2, $\quad-4, \quad-9$ ligands for additional $16 \mathrm{hr}$, a significantly enhanced production of $\mathrm{NO}$ and proinflammatory cytokines in response to TLR ligands - Zymosan A, LPS and CpG DNA was observed. However, macrophages pretreated with $T \alpha 1$ and further incubated with Poly I:C did not show enhanced NO and 
cytokine production as compared to macrophages treated with Poly I:C alone. This can be explained by the fact that, T $\alpha 1$ treatment does not result in the up regulation of TLR3 expression. In a third set of experiment murine peritoneal macrophages pretreated with $\mathrm{T} \alpha 1$ for $12 \mathrm{hr}$, washed and further incubated in fresh medium for additional $16 \mathrm{hr}$, the level of NO and proinflammatory cytokines produced were negligible (Fig.11\&12). This clearly suggests that T $\alpha 1$ priming leads to a synergistic production of nitric oxide and proinflammatory cytokines, which may be attributed to T $\alpha 1$ induced enhanced expression of TLRs.

The role of macrophages in the induction and regulation of innate immune responses has been well studied ${ }^{[36]}$. The ability of macrophages to recognize and respond to a diverse range of microbial ligands depend on the expression of a set of germ line encoded, pattern recognition receptors - TLRs. TLRs have been implicated as a crucial link between innate and adaptive immune responses. Therefore, the present observations on the enhanced expression and up regulation of TLRs together with the enhanced production of cytokines in response to $\mathrm{T} \alpha 1$ may have important implications in the generation of a robust immune response.

Originally identified for its role in differentiation of $\mathrm{T}$ lymphocytes, $\mathrm{T} \alpha 1$ has been shown to have immunoregulatory properties on a broad repertoire of cells, including, dendritic cells, macrophages and peripheral lymphocytes ${ }^{[20,21,26]}$. Synthetic $\mathrm{T} \alpha 1$ is in clinical trials worldwide for its therapeutic potential in several diseases, such as, chronic hepatitis B and C, acquired immune deficiency syndrome (AIDS), primary immunodeficiency diseases and cancer [21,37,38]. However, the molecular mechanism(s) of action of T $\alpha 1$, leading to the up regulation of TLRs are not well understood. It is not clear whether the immunomodulatory activities of $\mathrm{T} \alpha 1$ are due to a direct interaction between TLRs and T $\alpha 1$ or due to some indirect yet to be identified mechanism. Interest in T $\alpha 1$ stems mainly from the results of the clinical trials, which demonstrates it to be well tolerated with little or no adverse effects. Zadaxin has also been shown to promote the activity of the nuclear transcription factor, NF-kB through stimulation of TLR signaling pathway [21].

It is, therefore, concluded that T $\alpha 1$ induces an antigen independent activation of macrophages through the up regulation of TLRs. T $\alpha 1$ treatment primes murine peritoneal macrophages to become functionally more responsive to TLR ligands, through MyD88-IRAK1TRAF6 pathway. This leads to the activation of NF- $\kappa B$ and initiation of transcription of cytokine genes and their production. The studies can have potential applications in use of $\mathrm{T} \alpha 1$ as an adjuvant for vaccines and for the development of immunotherapeutic strategies. However, these in vitro studies need to be further supported by in vivo experiments and molecular mechanisms leading to the functional up regulation of TLRs by T $\alpha 1$ remains to be further elucidated.

\section{ACKNOWLEDGEMENT}

This work has been supported with research grant to Professor Ajit Sodhi from Department of Science and Technology, Government of India, New Delhi. Ms. Shikha Tarang is CSIR-SRF.

\section{REFERENCES}

1. Hoffmann, J.A., F.C. Kafatos, C.A. Janeway and R.A.B. Ezekowitz, 1999. Phylogenetic perspectives in innate immunity. Science, 284 (5418):313-1318.

2. Roach, J.C., G. Glusman, L. Rowen, A. Kaur, M.K. Purcell, K.D. Smith, L.E. Hood and A. Aderem, 2005. The evolution of vertebrate Tolllike receptors. PNAS, 102 (27): 9577-9582.

3. Muzio, M., D. Bosisio, N. Polentarutti, G. D'amico, A. Stoppacciaro, C. van't Veer, G. Penton-Rol, L.P. Ruco, P. Allavena and A. Mantovani, 2000. Differential expression and regulation of toll-like receptors (TLR) in human leukocytes: selective expression of TLR3 in dendritic cells. J. Immunol., 164 (11): 59986004.

4. Applequist, S.E., R.P.A. Wallin and H-G Ljunggren, 2001. Variable expression of Tolllike receptors in murine innate and adaptive immune cell lines. Int. Immunol., 14 (9): 10651074.

5. Gay N.J., M. Gangloff and N.A. Weber, 2006. Toll-like receptors as molecular switches. Nat. Rev. Immunol., 6(9): 693-698.

6. Bell, J.K., G.E.D. Mullen, C.A. Leifer, A. Mazzoni, D.R. Davies and D.M. Segal, 2003. Leucine- rich repeats and pathogen recognition in Toll-like receptors. Trends Immunol., 24 (10): 528-533.

7. Miggin, S.M. and L.A. O'Neill, 2006. New insights into the regulation of TLR signaling. J. Leuko. Biol., 80 (2): 220-226.

8. O' Neill, L.A. 2006. How Toll-like receptor signal: what we know and what we don't know. Curr. Opin. Immunol., 18(1):3-9. 
9. Akira, S., K. Takeda and T. Kaisho, 2001. Tolllike receptors: critical proteins linking innate and acquired immunity. Nat. Immunol., 2 (8):675680.

10. Beg, A.A. 2002. Endogenous ligands of Toll-like receptors: implications for regulating inflammatory and immune responses. Trends Immunol., 23 (11):509-512.

11. Anderson, K.V. 2000. Toll-signaling pathways in the innate immune response. Curr. Opin. Immunol., 12 (1):13-19.

12. Kammanadiminti, S.J., B.J. Mann, L. Dutil and K. Chadee, 2004. Regulation of Toll-like receptor 2 expression by the Gal-lectin of Entamoeba histolytica. FASEB J., 18 (1):155157.

13. Chang, J-H, J-Y. Park and S-K. Kim, 2006. Dependence on p38 MAPK signalling in the upregulation of TLR2, TLR4 and TLR9 gene expression in Trichomonas vaginalis-treated HeLa cells. Immunology, 118 (2): 164-170.

14. Akira, S. S. Uematsu and O. Takeuchi, 2006. Pathogen recognition and Innate Immunity. Cell, 124 (4):783-801.

15. Wang, S.S., H.H. Lee, R.J. Sokol and M.G. Mutchnick, 1980. Automated solid phase synthesis of thymosin $\alpha 1$. Int. J. Peptide Protein Res., 15 (1): 1-4.

16. Werts, C., S.E. Girardin and D.J. Philpott., 2006. TIR, CARD and PYRIN: three domains for an antimicrobial triad. Cell death and Diff., 13 (5): 798-815.

17. Kim, J.G., S.J. Lee and M.F. Kagnoff, 2004. Nod1 is an essential signal transducer in intestinal epithelial cells infected with bacteria that avoid recognition by Toll-like receptors. Infect. Immun., 72 (3): 1487-1495.

18. Opitz, B., A. Puschel, B. Schmeck, A.C. Hocke, S. Rosseau, S. Hammerschmidt, R.R. Schumann, N. Suttorp and S. Hippenstiel, 2004. Nucloetide-binding oligomerization domain proteins are innate immune receptors for internalized Streptococcus pneumoniae. J. Biol. Chem., 279 (35): 36426-36424.

19. Ferwada, G., S.E. Girardin, B-J. Kullberg, D. de Jong, D.M.L. Lagenberg, R. van Crevel, G.J. Adema, T.H.M. Ottenhoff, J.W.M. van der Meer and M.G. Netea, 2005. Nod2 and TLR2 are two non-redundent recognition systems of mycobacterium tuberculosis. PLoS Pathogens, 1 (3): 280-285.

20. Zhang, P., J. Chan, A-M. Dragoi, X. Gong, S. Ivanov, Z-W. Li, T. Chuang, C. Tuthill, Y. Wan, M. Karin and W-M. Chu, 2005. Activation of IKKby thymosin $\alpha 1$ requires the TRAF6 signaling pathway. EMBO rep., 6 (6):531-537.
21. Romani, L., F. Bistoni, R. Gaziano, S. Bozza, C. Montagnoli, K. Perruccio, L. Pitzurra, S. Bellocchio, A. Velardi, G. Rasi, P. di Franceso and E. Garaci, 2004. Thymosin $\alpha 1$ activates dendritic cells for antifungal Th1 resistance through toll-like receptor signaling. Blood, 103 (11): 4232-4239.

22. Billich, A. 2002. Thymosin alpha 1, SciClone Pharmaceuticals. Curr. Opin. Investig., 3 (5): 698-707.

23. Tarang, S., A. Sodhi and P. Chauhan, 2007. Differential expression of Toll-like Receptors in murine peritoneal macrophages, on in vitro treatment with cisplatin. Int. Immunol., doi:10.1093/intimm/dxm029.

24. Sodhi, A., S. Tarang and V. Kesherwani, 2007. Concanavlin A induced expression of Toll-like Receptors in murine peritoneal macrophages in vitro. Int. Immunophamacol., 7 (4): 454-463.

25. Sodhi, A. and S. Paul, 2002. Involvement of mitogen-activated protein kinases in the signal transduction pathway of bone marrow-derived macrophage activation in response to in vitro treatment with thymosin alpha 1 . Int. Immunopharmacol., 2 (1): 47-58.

26. Singh, R.K., A. Sodhi and S.M. Singh, 1991. Production of Interleukin-1 and Tumour Necrosis Factor by cisplatin treated murine peritoneal macrophages. Nat. Immun. Cell Growth Regul.,10 (2):105-116.

27. Wajant, H., F. Henkler and P. Scheurich, 2001. The TNF-receptor-associated factor family: scaffold molecules for cytokine receptors, kinases and their regulators. Cell Signal., 13 (6): 389-400.

28. Nilsen, N., U. Nonstad, N. Khan, C.F. Knetter, S. Akira, A. Sundan, T. Espevik and E. Lien, 2004. Lipopolysaccride and Double-stranded RNA Up regulate Toll-like Receptor 2 Independently of Myeloid Differentiation Factor 88. J. Biol. Chem., 279 (38): 39727-39735.

29. MacKay, R.J., R.R. King, J.R. Dankert, K.J. Reis and L.A. Skelley, 1991. Cytotoxic tumor necrosis factor activity produced by equine alveolar macrophage: preliminary characterization. Vet. Immunol. Immunophthol., 29 (1-2):15-30. 
30. Jiang W., J. Li, M. Gallowitsch-Pureta, K.J. Tracey and D.S. Pisetsky, 2005. The effects of CpG DNA on HMGB1 release by murine macrophages cell lines. J. Leuko. Biol., 78 (4): 930-936.

31. Brouet, I and H. Ohshima, 1995. Curcumin, an anti-tumor promoter and anti-inflammatory agent, inhibits induction of nitric oxide synthase in activated macrophages. Biochem and Biophy. Res. Comm., 206 (2): 533-540.

32. Sodhi, A. and G. Sethi, 2003. Involvement of MAP kinase signal transduction pathway in UV-B induced activation of macrophages in vitro. Immunol. Lett., 90 (2-3):123-130.

33. Ding A.H., C.F. Nathan and D.J. Stuecher, 1988. Release of reactive nitrogen intermediate from mouse peritoneal macrophages: comparison of activating cytokines and evidences for independent production. J. Immunol., 14 (7):12407-2412.
34. Katherine, A.F., C.R. Daniel, J.B. Betsy, R.C. Daniel, V. Alberto, L. Eicke, M. Brian, M.P. Paula and T.G. Douglas, 2003. LPS-TLR4 Signaling to IRF-3/7 and NF- $\kappa B$ involves the Toll Adapters TRAM and TRIF. J. Exp. Med., 198 (7):1043-1055.

35. Takeda, K. and S. Akira, 2005. Toll-like receptors in innate immunity. Int. Immunol., 17(1):1-14.

36. Takeda, K. 2005. Toll-like receptors and their adaptors in innate immunity. Curr. Med. Chem., 4 (1):3-11.

37. Wara, D.W., A.L. Goldstein, N.E. Doyle and A.J. Amman, 1975. Thymosin activity in patients with cellular immunodeficiency. N. Engl. J. Med., 292 (2):70-74.

38. Garaci, E., F. Pica, G. Rasi and C. Favalli, 2000. Thymosin alpha 1 in the treatment of cancer: from basic research to clinical application. Int. J. Immunopharmacol., 22 (12):1067-1076. 